\title{
Hydrology: Asian glaciers are a reliable water source
}

The people, economies and agriculture of central Asia and parts of south Asia rely on water from mountains. Modelling suggests that glacier melt, in particular, is a key water source during dry periods in some of these regions. See Article p. 169.

Water availability is fundamental to food production, the economy, hydropower and the public health of any country. However, supplying water is challenging in central and parts of south Asia, whose economies depend heavily on agriculture ${ }^{1}$. Climate change could further exacerbate water shortages in these regions. On page 169, Pritchard ${ }^{2}$ reports that glaciers are essential sources of fresh water in the western river basins of the high-mountain Asia region (those located in Pakistan, Tajikistan, Uzbekistan, Kyrgyzstan and Xinjiang in northwestern China), particularly during droughts. These regions receive little precipitation during summer, when water demand for irrigation is highest. The new findings raise questions about water security in Asia, given that global warming is projected to continue.

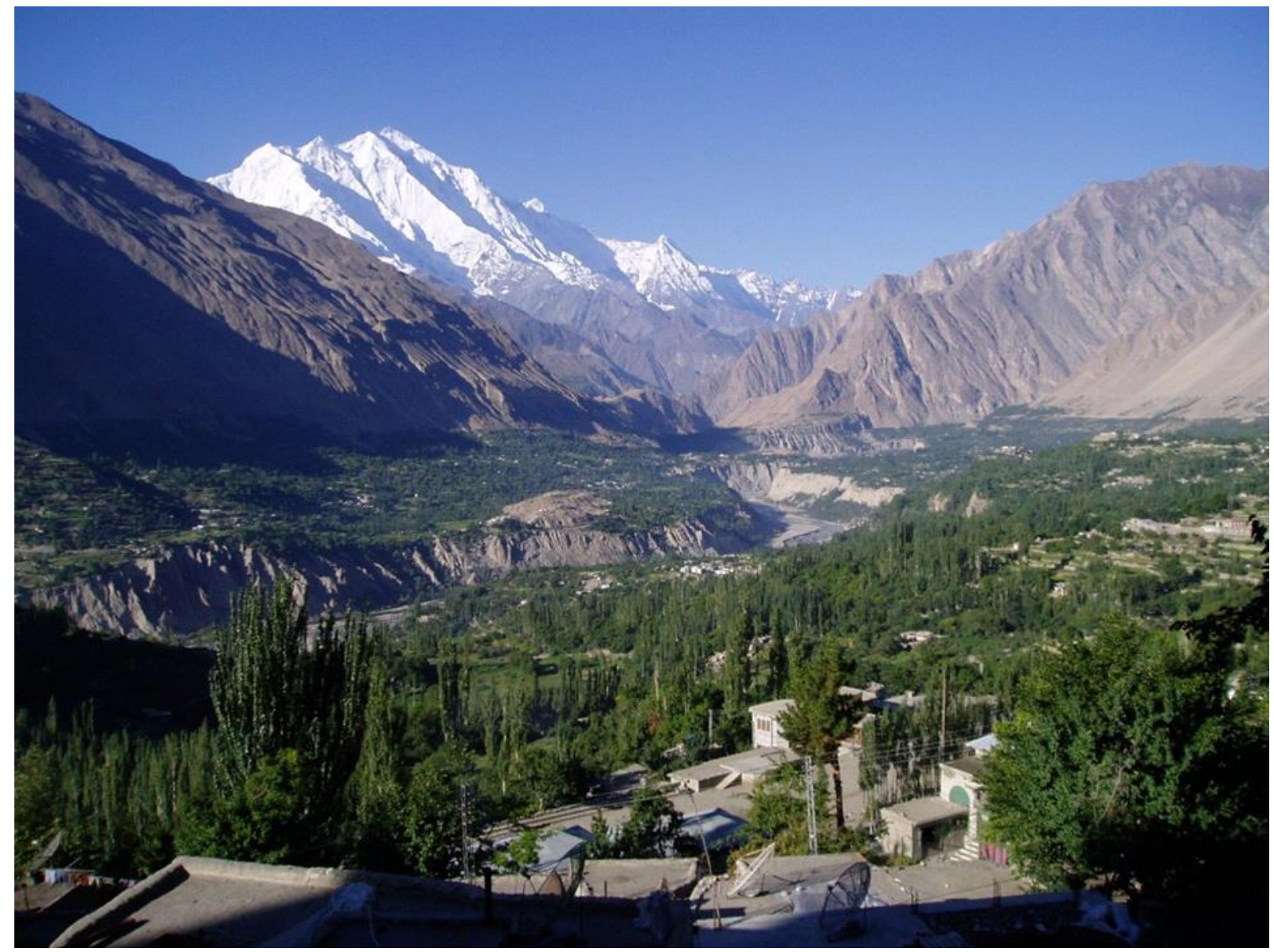

Figure 1: The Hunza valley in the Karakoram mountains: Many regions in central and south Asia, such as the Hunza Valley, receive little precipitation, and rely on water from the surrounding mountains for agriculture. Pritchard ${ }^{2}$ reports that meltwater from glaciers is a crucial source of water in these areas during droughts. Photo: T. Bolch.

Most major rivers originating in high-mountain Asia pass through different countries, and downstream countries such as Uzbekistan and Turkmenistan rely on water from upstream ones. The current and future states of river discharge are therefore matters of high political sensitivity ${ }^{3}$. Political tensions over water availability are further exacerbated by existing and planned hydropower 
Bolch, T., 2017. Hydrology: Asian glaciers are a reliable water source. Nature 545 (7653), 161-162. doi:10.1038/545161a; also available at: http://rdcu.be/rVmY

dams. Upstream countries, such as Kyrgyzstan, Tajikistan and Nepal, rely on hydropower - for example, the Toktogul hydropower plant and four smaller plants downstream produce almost $80 \%$ of Kyrgyzstan's electricity ${ }^{4}$. A large amount of water is usually released from central Asian hydropower reservoirs during winter, when electricity demand is highest, but water for irrigation is needed during summer ${ }^{3}$. Pritchard's results are thus societally highly relevant.

Previous work (see refs 5 and 6, for example) has shown that glacier meltwater provides many Asian rivers with continuous water flow, and that this is crucial in regions that receive low summer precipitation. Glacier melt is less important in the river catchments (areas where precipitation drains into a specific river) of the eastern Himalayas that are dominated by summer monsoons. But even in these catchments, glaciers can be a crucial source of water when monsoon precipitation is low.

The major strength of Pritchard's work is that he quantifies the contribution of glacier meltwater during drought periods for different regions. He clearly shows that this water has the biggest role in the Indus River and Aral Sea catchments, where the fraction contributed by glaciers dominates the available water. Indeed, glacier melt can be almost the sole water source in areas close to glaciers in the Aral Sea catchments during drought months.

Another strength of the study is that it reveals the value of glacier melt for hydropower production. For example, annual melt from glaciers upstream of Pakistan's largest hydropower reservoir (the Tarbela reservoir) accounts for more than two-thirds of the reservoir's storage volume, even in years that have average precipitation. Pritchard also highlights the fact that glaciers provide a crucial ecosystem service - they act as a reliable source of water that can be considered in decision-making processes about sustainable water management ${ }^{7}$.

But although Pritchard defines the current key role of glaciers, the future amount of glacial run-off remains unknown. Glaciers act as long-term water-storage systems by accumulating mass obtained mainly from snowfall, and release water only when the temperature is high enough to melt the ice. If glaciers lose mass, for example because of climate change, they will contribute more to river run-off.

However, if glaciers continue to shrink, their contribution will eventually start to decrease. Current estimates suggest with high confidence that most Asian glaciers will significantly retreat until the end of this century (see ref. 8, for example; no projections are available beyond 2100). But some regions, such as the Karakoram mountain range, have relatively high ice volumes ${ }^{9}$, and glaciers in central Karakoram have been fairly stable since at least the 1970s (ref. 10). Hence, glacier run-off in several catchments of the upper Indus located in Karakoram (Fig. 1) will probably not decline by much, even in the long term. Run-off projections for rivers originating in the Himalayas and Karakoram indicate that river flows will increase until at least the middle of the twenty-first century ${ }^{11}$. By contrast, projections for arid central Asia suggest that river discharge will start to decline in the next few decades $^{12}$.

Such projections have large uncertainties, because there is especially low confidence in projections for future changes in precipitation ${ }^{1}$. This is partly because of uncertainty over the future behaviour of the monsoon system, but also because there are almost no weather stations at high elevations in Asia (or indeed elsewhere). To improve modelling and predictions of glacier melt, the effects of debris cover on glaciers needs to be better understood; debris-covered glaciers are common in highmountain Asia.

We also need to know more about the impact of glacier surging - the periodic, rapid advance of glaciers as a result of relatively fast relocation of ice mass from upper to lower parts of the glacier. 
Bolch, T., 2017. Hydrology: Asian glaciers are a reliable water source. Nature 545 (7653), 161-162. doi:10.1038/545161a; also available at: http://rdcu.be/rVmY

Other factors to consider are the roles of permafrost and groundwater storage ${ }^{13}$. To obtain better models, we also need expanded observational networks for studying run-off, climate (especially at high elevations) and glaciers (in particular, their mass balances and thicknesses), and remote-sensing studies of glacier-mass changes. Finally, open access to existing data is highly desirable, or datasharing agreements are needed, at the very least.

\section{References:}

1. Hijioka Y. et al. in Climate Change 2014: Impacts, Adaptation, and Vulnerability (eds Barros, V. R. et al.) 1327-1370 (Cambridge Univ. Press, 2014).

2. Pritchard, H. D. Nature 545, 169-174 (2017).

3. Bernauer, T. \& Siegfried, T. J. Peace Res. 49, 227-239 (2012).

4. The World Bank. Water Energy Nexus in Central Asia: Improving Regional Cooperation in the Syr Darya Basin (2004).

5. Kaser, G., Grosshauser, M. \& Marzeion, B. Proc. Natl Acad. Sci. USA 107, 20223-20227 (2010).

6. Immerzeel, W. W. \& Bierkens, M. F. P. Nature Geosci. 5, 841-842 (2012).

7. Rumbaur, C. et al. Earth Syst. Dynam. 6, 83-107 (2015).

8. Huss, M. \& Hock, R. Front. Earth Sci. 3, 54 (2015).

9. Frey, H. et al. Cryosphere 8, 2313-2333 (2014).

10. Bolch, T., Pieczonka T., Mukherjee, K. \& Shea, J. Cryosphere 11, 531-539 (2017).

11. Lutz A. F., Immerzeel, W. W., Shrestha, A. B. \& Bierkens, M. F. P. Nature Clim. Change 4, 587-592 (2014).

12. Duethmann, D., Menz, C., Tong, J. \& Vorogushyn, S. Environ. Res. Lett. 11, 054024 (2016).

13. Andermann, C. et al. Nature Geosci. 5, 127-132 (2012). 